\title{
Electrochemical deposition of a copper carboxylate layer on copper as potential corrosion inhibitor
}

\author{
Alice Elia ${ }^{\mathrm{a}}$, Karolien De Wael ${ }^{\mathrm{a} 1}$, Mark Dowsett ${ }^{\mathrm{b}}$ and Annemie Adriaens ${ }^{\mathrm{a} *}$ \\ ${ }^{a}$ Department of Analytical Chemistry, Ghent University, Krijgslaan 281, B-9000 \\ Ghent, Belgium \\ ${ }^{b}$ Department of Physics, University of Warwick, Coventry CV4 7AL, UK
}

* Corresponding author. Tel: +32 926448 26; fax: +32 926449 60; email:

Annemie.Adriaens@UGent.be

\begin{abstract}
Carboxylic acids and sodium carboxylates are used to protect metals against aqueous and atmospheric corrosion. In this paper we describe the application of a layer of copper carboxylate on the surface of a copper electrode by means of cyclic voltammetry technique, and tests which measure the corresponding resistance to aqueous corrosion. Unlike the soaking process, which also forms a film on the surface, the use of cyclic voltammetry allows one to follow the deposition process of the copper carboxylates onto the electrode. The modified electrodes have been characterized with infrared spectroscopy. In addition the corrosion resistance of the film has been investigated using polarization resistance and Tafel plot measurements
\end{abstract}

Keywords: Copper carboxylates, cyclic voltammetry, corrosion inhibition, infrared spectroscopy, cultural heritage

\section{Introduction}

Copper has played an important role in human development. The earliest use of native copper was at least 10,000 years ago, and the first copper-based alloys were produced in the $4^{\text {th }}$ millennium B.C. The intrinsic advantages of copper, such as easy extraction and handling, as well as excellent heat conduction, make it an ideal utilitarian metal. Additionally, copper and its alloys were (and still are) appreciated as decorative metals which have been used throughout history for the realization of various art objects, from jewellery to statuary.

\footnotetext{
${ }^{1}$ Postdoctoral Fellow of the Research Foundation - Flanders (Belgium)
} 
As with many other metals, copper corrodes once it comes into contact with an aggressive environment, for example the sea or the atmosphere. In the field of art, copper-based objects are often preferred in the corroded state, not only because of the aesthetically pleasing colours, but also because the presence of corrosion products provides evidence of time past and time passing, thereby adding extra value to the object. However, corrosion may also become a problem, especially when specific corrosion products (such as cuprous chlorides) are in contact with the metal core. Under certain conditions, the deterioration of the underlying metal will continue and will lead to the destruction of the object.

The use of corrosion inhibitors is thus necessary in order to preserve the characteristics of the material. Inorganic ions, such as $\mathrm{CrO}_{4}{ }^{2-}$ and $\mathrm{B}_{4} \mathrm{O}_{7}{ }^{2-}$, form a passivating layer of metal oxide on the copper surface, but their used is limited due to the high toxicity [1,2]. Organic coating and inhibitors have been used since antiquity. Wax and oils for instance were commonly used to protect copper and bronze objects [3]. More recently copper corrosion inhibitors include a large variety of organic compounds, such as azoles and amines [2], thiurea and triazole derivatives [4], amino acids (and their derivatives) and sodium salts of saturated carboxylic acids [5-18].

Saturated monocarboxylic chains have been tested as corrosion inhibitors for various metals, including copper. They are environmental friendly as they do not contain sulphur, aromatic rings or nitrogen. Their effectiveness has been discussed in various studies [6-18], not only as a general corrosion inhibitor, but also in the framework of treating cultural artefacts [7-12]. Crystalline layers of metal carboxylate are formed by immersion of the metal in the solution containing the corresponding carboxylic acid. Previous studies have shown that the length of the carboxylic chain, in particular, is very important: longer chains provide better protection against aggressive agents [8-10]. In general these compounds act via adsorption on the metal surface and the formation of complexes [2].

With regard to copper protection, there are only few studies which investigate the formation of layers of copper carboxylates from aqueous [8] and ethanolic solutions [17,18]. Amongst the advantages of these compounds, there is the minor toxicity in respect to other harmful organic inhibitors for copper corrosion, such as benzotriazole [19].

In this paper, the aim is to electrochemically deposit a layer of copper carboxylate on a copper electrode surface, from an aqueous solution of sodium carboxylates by means of cyclic voltammetry. The use of cyclic voltammetry allows us to control the deposition processes while the carboxylate layer is forming in comparison to mere immersion of the samples as has been done in the studies mentioned above. The same procedure has already been applied to lead electrodes, leading to the formation of a lead carboxylate layer effective against corrosion in an aggressive environment [5]. 
Three types of carboxylates were studied and compared: heptanoate, decanoate and dodecanoate. The deposition was performed using the respective sodium carboxylates $\left(\mathrm{NaC}_{\mathrm{n}}\right)$ as they tend to have a better solubility in water than the related carboxylic acid [20]. The modified electrodes were characterized using Fourier Transform infrared spectroscopy (FTIR). In addition polarization and Tafel plot experiments were performed to evaluate the inhibition effect of the three carboxylate layers.

\section{Experimental}

Three different sodium carboxylate solutions were used for the experiments: sodium heptanoate $\left(\mathrm{NaC}_{7}\right)$, sodium decanoate $\left(\mathrm{NaC}_{10}\right)$ and sodium dodecanoate $\left(\mathrm{NaC}_{12}\right)$ with each a concentration of $0.025 \mathrm{M}$. The solutions were prepared by neutralizing to $\mathrm{pH} 7.0$ the respective carboxylic acid with sodium hydroxide $(\mathrm{NaOH})$. For $100 \mathrm{ml}$ of deionised water the following quantities were weighed: heptanoic acid $\left(\mathrm{HC}_{7}\right.$, purity $\left.>97 \%\right) 0.325 \mathrm{~g}$, decanoic acid $\left(\mathrm{HC}_{10}\right.$, purity $\left.\geq 98 \%\right) 0.431 \mathrm{~g}$ and dodecanoic acid $\left(\mathrm{HC}_{12}\right.$, purity $\left.98 \%\right) 0.501 \mathrm{~g}$. A reference solution was also prepared by dissolving the same quantity of $\mathrm{NaOH}$ in water used to neutralize the carboxylic acids, i.e. a 0.025 $\mathrm{M}$ solution. The sodium carboxylate and reference solutions were purged with nitrogen for 15 minutes before each experiment. All chemical products used for the experiments were purchased from Sigma Aldrich.

Experiments were carried out in a three electrode electrochemical cell, using a saturated calomel electrode (SCE) as a reference electrode (Radiometer Analytical, France) and a carbon rod as a counter electrode. The working electrode was a pure copper rod (diameter $2 \mathrm{~mm}$, purity $99.99 \%$ purchased from Goodfellow) embedded in epoxy resin. A computer controlled potentiostat with the software package GPES 4.9005 (Autolab PGSTAT20, ECO Chemie) was used for all measurements. All the potentials given in this paper are in reference to the SCE.

Prior to each experiment the electrode was mechanically cleaned with silicon carbide ( $\mathrm{SiC}$ ) paper of P1200 grit to obtain a fresh surface. The surface was subsequently polished using a polishing cloth and an alumina $\left(\mathrm{Al}_{2} \mathrm{O}_{3}\right)$ water suspension $(1 \mu \mathrm{m}$ particle size $)$. To remove any adhering $\mathrm{Al}_{2} \mathrm{O}_{3}$ particles, the electrode was rinsed with deionised water and ultrasonically cleaned in ethanol for 15 minutes.

The modification of the copper electrode by carboxylate was performed by recording successive cyclic voltammetric scans (100 scans) in a potential window from -1.1 to $0.6 \mathrm{~V}$ vs SCE with a scan rate of $50 \mathrm{mV} / \mathrm{s}$. After each modification procedure, the electrode was rinsed with deionised water.

The electrochemical properties of the modified electrode were then evaluated by means of linear sweep voltammetry (LSV) in a $0.1 \mathrm{M} \mathrm{Na}_{2} \mathrm{SO}_{4}$ solution: the polarization resistance $\left(R_{\mathrm{p}}\right)$ was measured in a range of $\pm 20 \mathrm{mV}$ vs the open circuit potential (OCP) at a scan rate of $1 \mathrm{mV} / \mathrm{s}$. The 
corrosion current was calculated via the Tafel extrapolation from the LSV curve recorded in a range of $\pm 250 \mathrm{mV}$ vs OCP with a scan rate of $0.2 \mathrm{mV} / \mathrm{s}$.

Infrared spectroscopic analyses were performed in order to obtain qualitative proof of the deposition of a copper carboxylate layer. The spectra were recorded in reflectance mode in the range 4000-600 $\mathrm{cm}^{-1}$ using a Biorad FT-IR spectrometer FTS 575C equipped with a "Golden Gate" ATR accessory fitted with a diamond crystal.

\section{Results and discussion}

Figure 1 represents the potentiodynamic curve of a copper electrode in the reference solution, $\mathrm{NaOH} 0.025 \mathrm{M}$, to which no corrosion inhibitors had yet been added. Three anodic peaks are clearly visible showing the oxidation to different copper species.

Peaks A1 $(-0.35 \mathrm{~V})$ and $\mathrm{A} 2(-0.14 \mathrm{~V})$ are related to the oxidation to $\mathrm{Cu}_{2} \mathrm{O}$ and $\mathrm{CuO}$ respectively, as described in previous studies [21-24]. They can be explained using the reactions (1) and (2):

$2 \mathrm{Cu}+2 \mathrm{OH}^{-} \rightarrow \mathrm{Cu}_{2} \mathrm{O}+\mathrm{H}_{2} \mathrm{O}($ peak A1)

$\mathrm{Cu}_{2} \mathrm{O}+2 \mathrm{OH}^{-} \rightarrow 2 \mathrm{CuO}+\mathrm{H}_{2} \mathrm{O}($ peak A2)

The broad shape of peak A3 (in the potential region between 0.01 and $0.46 \mathrm{~V}$ ) can be attributed to the formation of a $\mathrm{Cu}(\mathrm{OH})_{2}$ layer from the hydration of the cupric oxide layer [21].

In the cathodic curve, peaks $\mathrm{C} 1(-0.86 \mathrm{~V})$ and $\mathrm{C} 2(-0.49 \mathrm{~V})$ are associated to the reduction processes of copper oxides and hydroxides formed during the oxidation according to equations (3) and (4):

$2 \mathrm{CuO}+\mathrm{H}_{2} \mathrm{O} \rightarrow \mathrm{Cu}_{2} \mathrm{O}+2 \mathrm{OH}^{-}($peak $\mathrm{C} 1)$

$\mathrm{Cu}_{2} \mathrm{O}+\mathrm{H}_{2} \mathrm{O} \rightarrow 2 \mathrm{Cu}+2 \mathrm{OH}^{-}($peak $\mathrm{C} 2)$

Figure 2 shows the electrochemical behaviour of the copper electrode in the three different sodium carboxylate solutions, $\mathrm{NaC}_{7}, \mathrm{NaC}_{10}$ and $\mathrm{NaC}_{12}$, after 100 cycles. In the three curves presented, there are no clear peaks identifiable as related to the oxidation processes observed before in Figure 1. Moreover compared with the copper electrode in $\mathrm{NaOH}$, the range of the current is definitely smaller for all the sodium carboxylates used.

The amount of total current is larger in the voltammogram of copper in $\mathrm{NaC}_{7}$ solution, while it is progressively reduced in the $\mathrm{NaC}_{10}$ and $\mathrm{NaC}_{12}$ solutions. $\mathrm{NaC}_{12}$ produces the most evident 
reduction in the total amount of current. This decrease can be explained with an inhibition effect of the carboxylate in the solution and the progressive deposition of a copper carboxylate layer on the electrode surface.

Figure 3 shows three voltammograms (scan 2, 10 and 100) obtained from a copper electrode in $\mathrm{NaC}_{12}$ solution $(0.025 \mathrm{M})$. The decrease of total current flow is visible comparing successive cycles, and the signal is already stable after the $10^{\text {th }}$ scan, indicating a progressive deposition of a layer of copper carboxylate.

For all sodium carboxylates used, the electrode modification was stopped after 100 cycles. Copper carboxylates typically show a blue-green colour $[17,18]$, but observations of the electrodes carried out with the optical microscope did not show any difference between the surface appearance before and after the modification, as expected in the case of a very thin layer. Nevertheless, FTIRATR analyses on electrodes modified using $\mathrm{NaC}_{10}$ and $\mathrm{NaC}_{12}$ confirm the deposition of copper carboxylates on the surface.

On the copper electrode treated with $\mathrm{NaC}_{7}$ it was not possible to observe the presence of a copper heptanoate $\left(\mathrm{CuC}_{7}\right)$ layer with infrared analyses. This can be explained if the copper heptanoate layer was too thin to be detected by FTIR.

In Figure 4 the FTIR-ATR spectrum of a copper electrode after 100 cycles in a $\mathrm{NaC}_{10} 0.025 \mathrm{M}$ solution is compared to the spectrum of a bare copper electrode. The spectrum shows two absorption peaks at 2849 and $2917 \mathrm{~cm}^{-1}$, which are related to the symmetric and asymmetric stretching vibrations of $\mathrm{CH}$ bonding [25-27]. The frequencies of the absorption bands of the carbonyl group (symmetric and asymmetric stretching) are in the region of $1350-1750 \mathrm{~cm}^{-1}$. In the spectrum presented, the asymmetric $\mathrm{COO}$ - stretching of copper decanoate $\left(\mathrm{CuC}_{10}\right)$ is visible at $1588 \mathrm{~cm}^{-1}$. The absorption frequency of the COO- stretching is highly sensitive to the structure of the carboxylate group and the identity of the metal ion [25-27] and allows us to distinguish between carboxylic acid, sodium carboxylate and copper carboxylate [26].

Infrared analyses on reference materials of sodium carboxylates, carboxylic acids and copper carboxylates synthesized in the laboratory (not shown) confirm the attribution of the carbonyl absorption frequencies to copper compounds. Absorption bands characteristic of copper carboxylates were present in all the electrodes modified with $\mathrm{NaC}_{10}$ and $\mathrm{NaC}_{12}$.

Finally, the corrosion resistance of the copper carboxylate layer was evaluated using polarization techniques. Figure 5 presents the polarization curves for the electrodes modified using carboxylates of different chain length. Table 1 shows the average of four experiments and their relative standard deviation $(\mathrm{RSD})$ of polarization resistance values obtained from the polarization curves. The analyses reveal the absence of a deposited layer of copper heptanoate on the electrode (as suspected from the FTIR data) as the polarization resistance of the electrode modified with 
$\mathrm{NaC}_{7}$, in fact, is very close to the value of polarization resistance $\left(R_{\mathrm{p}}\right)$ of clean copper. Given the results obtained from optical microscopy, FTIR and polarization techniques, it was decided to discard the electrodes modified with $\mathrm{CuC}_{7}$ in the subsequent polarization experiments.

The deposition of a copper decanoate $\left(\mathrm{CuC}_{10}\right)$ and copper dodecanoate $\left(\mathrm{CuC}_{12}\right)$ coating, on the other hand, increases the polarization resistance of the electrode. In Figure 5 it is possible to observe that samples treated with $\mathrm{NaC}_{10}$ and $\mathrm{NaC}_{12}$ show a minor slope. This is an indication of the protective effect of the carboxylate layer deposited on the surface. The increment of the polarization resistance is related to the chain length: longer aliphatic chains provide better protection, while in the case of copper heptanoate it is not possible to observe a protective effect.

The Tafel extrapolation of the linear polarization curves is presented in Figure 6. The presence of a $\mathrm{CuC}_{10}$ and $\mathrm{CuC}_{12}$ layer on the electrode surface produces a shift of the corrosion potential towards more negative values and reduces clearly the corrosion current. The decrease of the corrosion current is more evident in case of the presence of $\mathrm{CuC}_{12}$ layer which gives a better protection against corrosion.

Table 2 presents the average value for the corrosion current density $\left(i_{\text {corr }}\right)$ obtained from these experiments. The inhibition efficiency (IE) can be calculated using equation (5) [17]:

$$
I E(\%)=\frac{i_{\text {(clean) }}-i_{\text {(coated) }}}{i_{\text {(clean) }}} \times 100
$$

This parameter is useful to compare the decrease in corrosion current produced by different coatings. The corrosion current density and the inhibition efficiency values are consistent and confirm the results of the polarization resistance experiment. The copper carboxylates $\mathrm{CuC}_{12}$ and $\mathrm{CuC}_{10}$ reduce the corrosion current and $\mathrm{CuC}_{12}$ deposited on the electrode surface is more effective than $\mathrm{CuC}_{10}$ in inhibiting the corrosion process.

As a negative point it must be noticed that the relative standard deviation is very high, indicating that a large variability of the $i_{\text {corr }}$ values has been encountered. This could be due to varying layer thicknesses for the copper carboxylate on the surface or to heterogeneity of the layer. Other causes may be the softness of carboxylate soaps already observed in previous studies [18] and their consequent susceptibility to mechanical damage, or differing amounts of hydration of the layers themselves permitting some ion transfer. Further investigation is required here because of the implications for both aqueous and atmospheric corrosion protection.

\section{Conclusions}

This work shows that it is possible to apply a layer of copper decanoate and copper dodecanoate by electrochemical means. This was confirmed using infrared spectroscopy. The modified electrodes are visually indistinguishable from pure copper. 
Although the polarization resistance of copper electrode modified with $\mathrm{CuC}_{10}$ and $\mathrm{CuC}_{12}$ is increased by the coating deposition, the analyses of $i_{\text {corr }}$ show a high relative standard deviation. More research is indeed needed to better understand the formation of the copper carboxylate layer by means of electrochemical deposition and to improve the reproducibility of the process. Nevertheless, compared to the soaking process, cyclic voltammetry is indeed a useful tool to follow and control the deposition process.

\section{Acknowledgments}

Authors would like to acknowledge the Research Foundation - Flanders (FWO) for funding assistance (A. Elia is a FWO aspirant) and V. Vermeersch and S. Van Vlierberghe (Ghent University, Polymer Chemistry and Biomaterials Research Group) for the FTIR-ATR measurements.

\section{References}

1. Igual Muñoz MA, García Antón J, Guiñón JL, Pérez-Herranz V (2004) Electrochim Acta 50:957-966

2. Antonijevic MM, Petrovic MB (2008) Int J Electrochem Sc 3:1-28

3. Scott DA (2002), Copper and bronze in art. Corrosion, colorants and conservation, Getty Publications, Los Angeles

4. Bastidas DM, Cano E, Mora EM (2005) Anti-Corros Meth Mater 52:71-77

5. Bastidas DM, Criado M, Fajardo S, La Iglesia VM, Cano E, Bastidas JM (2010) Int Mater Rev 55:99-127

6. De Wael K, De Keersmaecker M, Dowsett M, Walker D, Thomas PA, Adriaens A (2010) J Solid State Electr 14:449-451

7. Dowsett M, Adriaens A, Schotte B, Jones G, Bouchenoire L (2007) In Degrigny C, van Langh R, Joosten I, Ankersmith B (Eds) Metal 07 (Book 3) Rijksmuseum Amsterdam, Amsterdam

8. Hollner S, Mirambet F, Texier A, Rocca E, Steinmetz J (2007) In Argyropoulos V, Hein A, Abdel Harith M (Eds) Strategies for Saving our Cultural Heritage, TEI of Athens, Athens

9. Hollner S, Mirambet F, Rocca E, Steinmetz J (2007) In Degrigny C, van Langh R, Joosten I, Ankersmith B (Eds) Metal 07 (Book 3) Rijksmuseum Amsterdam, Amsterdam

10. Rocca E, Steinmetz J (2001) Corros Sci 43:891-902

11. Rocca E, Rapin C, Mirambet F (2004) Corros Sci 46: 653-665

12. Adriaens A, De Bisschop F, Dowsett M, Schotte B (2008) Appl Surf Sci 254:7351-7355

13. Georges C, Rocca E, Steinmetz P (2008) Electrochim Acta 53:4839-4845

14. Stein N, Johann L, Rapin C, Lecuire JM (1998) Electrochim Acta, 43:3227-3234

15. Rocca E, Bertrand G, Rapin C, Labrune JC (2001) J Electroanal Chem 503:133-140

16. Bertrand G, Rocca E, Savall C, Rapin C, Labrune JC, Steinmetz P (2000) J Electroanal Chem 489:38-45

17. Milošev I, Kosec T, Bele M (2010) J Appl Electrochem 40:1317-1323 
18. Elia A, Dowsett M, Adriaens A (2010) In Mardikian P, Chemello C, Watters C, Hull P (Eds) Metal 10, Clemson University, Clemson

19. Health Council of the Netherlands (2002) 1,2,3-Benzotriazole. Health-based recommended occupational exposure limit. Available via http://www.gezondheidsraad.nl/en/publications/123-benzotriazole-health-basedrecommended-occupational-exposure-limit. Accessed 23 Aug 2010

20. Aylward GH, Findlay T (1998) SI Chemical Data Book 4th ed. Wiley, Brisbane

21. Babić R, Metikoš-Huković M, Jukić A (2001) J Electrochem Soc 148:146-151

22. Assaf FH, Zakya AM, Abd El-Rehim SS (2002) Appl Surf Sci 187:18-27

23. Bogdanowicz R, Ryl J, Darowicki K, Kosmowski BB (2009) J Solid State Electr 13:16391644

24. Procaccini R, Vázqueza M, Ceré S (2009) Electrochim Acta 54:7324-7329

25. Nakamoto K (1978) Infrared and Raman spectra of Inorganic and Coordination Compounds 3rd ed. Wiley Interscience, New York

26. Papageorgiou SK, Kouvelos EP, Favvas EP, Sapalidis AA, Romanos GE, Katsaros FK (2010) Carbohyd Res 345: 469-473

27. Palacios EG, Juárez-López G, Monhemius AJ (2004) Hydrometallurgy 72:139-148 


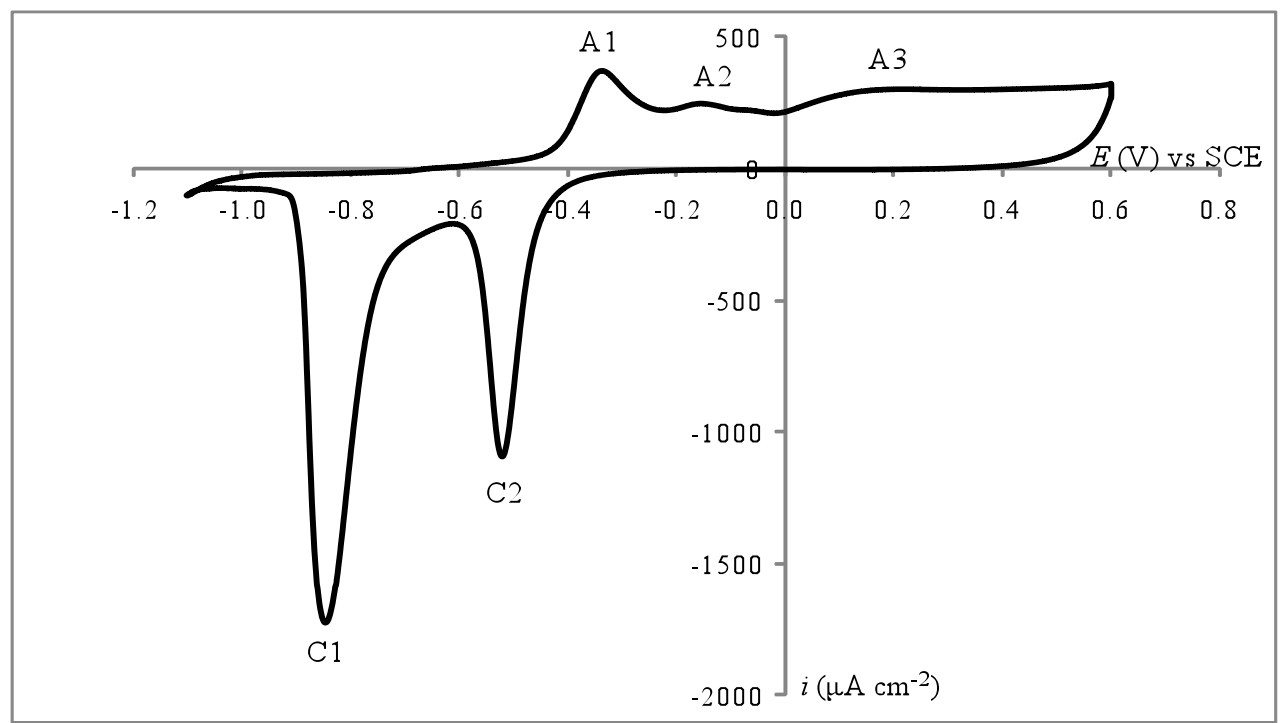

Fig. 1 The current potential behaviour of a copper electrode in a $0.0025 \mathrm{M} \mathrm{NaOH}$ solution with a scan rate of $50 \mathrm{mV} / \mathrm{s}$

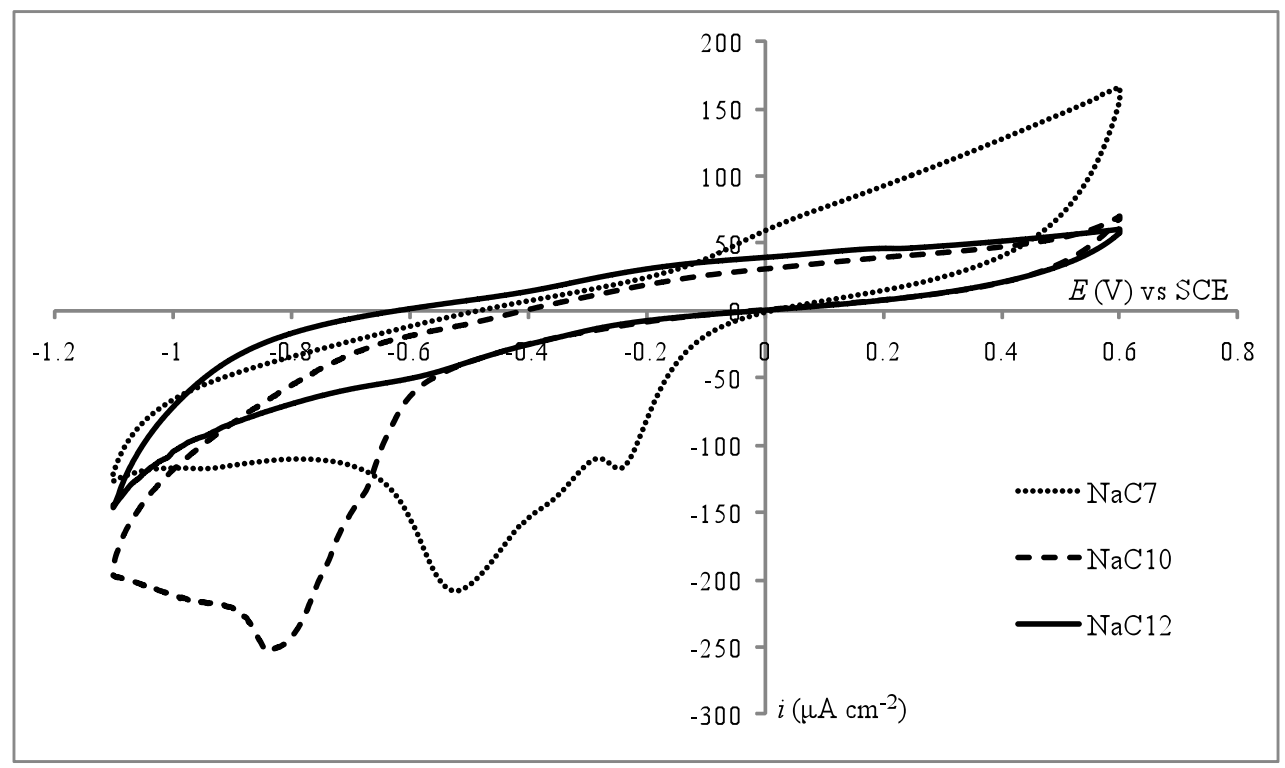

Fig. 2 Potentiodynamic curves of a copper electrode in $\mathrm{NaC}_{7}, \mathrm{NaC}_{10}$ and $\mathrm{NaC}_{12}(0.025 \mathrm{M})$ 


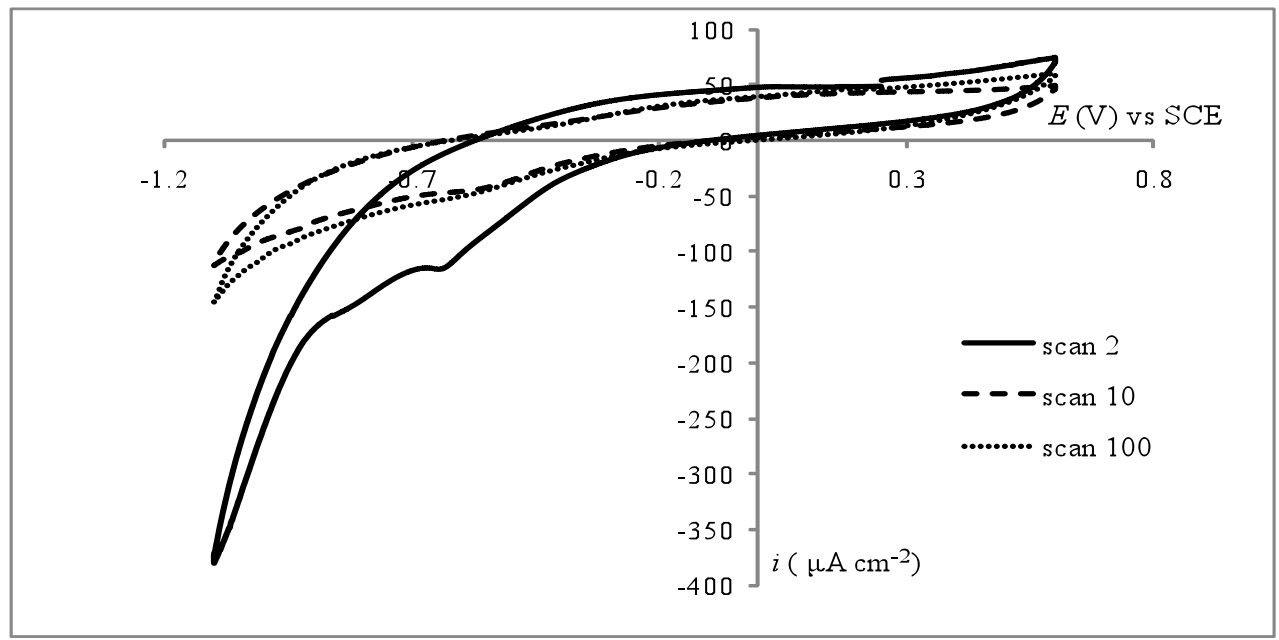

Fig. 3 Voltammetric scans of a copper electrode in $\mathrm{a} \mathrm{Na}_{12} 0.025 \mathrm{M}$ solution (scan 2, 10 and 100)

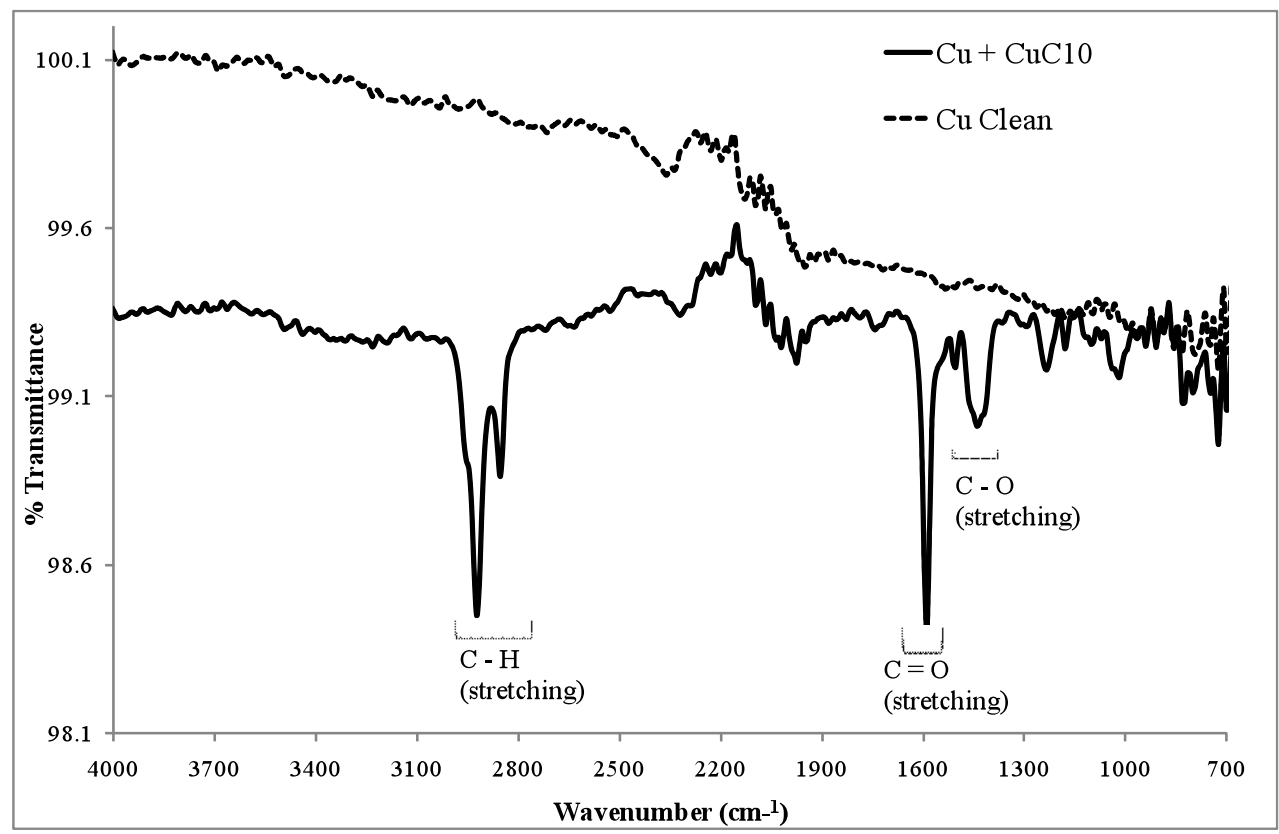

Fig. 4 FTIR-ATR spectra of a bare $\mathrm{Cu}$ electrode and a $\mathrm{Cu}$ electrode after 100 cycles in $0.025 \mathrm{M}$ $\mathrm{NaC}_{10}$ solution 


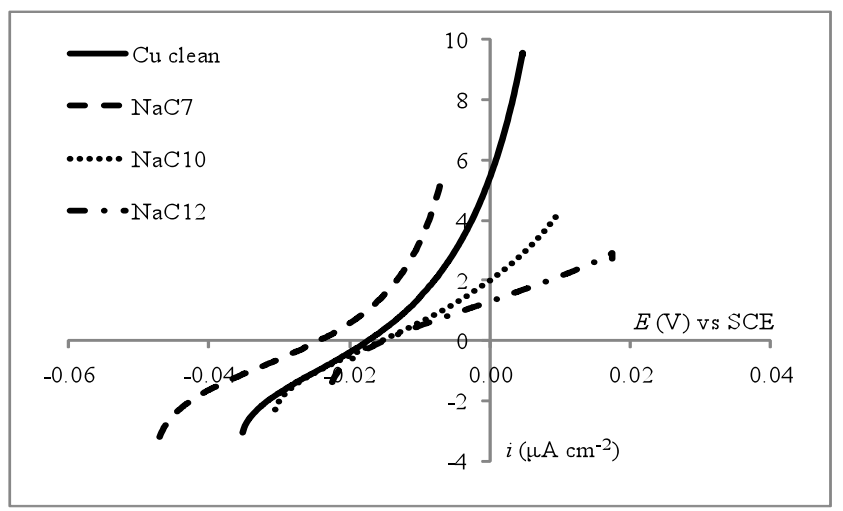

Fig. 5 Polarization curves for a copper electrode modified with different carboxylates. The electrolyte is $0.1 \mathrm{M} \mathrm{Na}_{2} \mathrm{SO}_{4}$

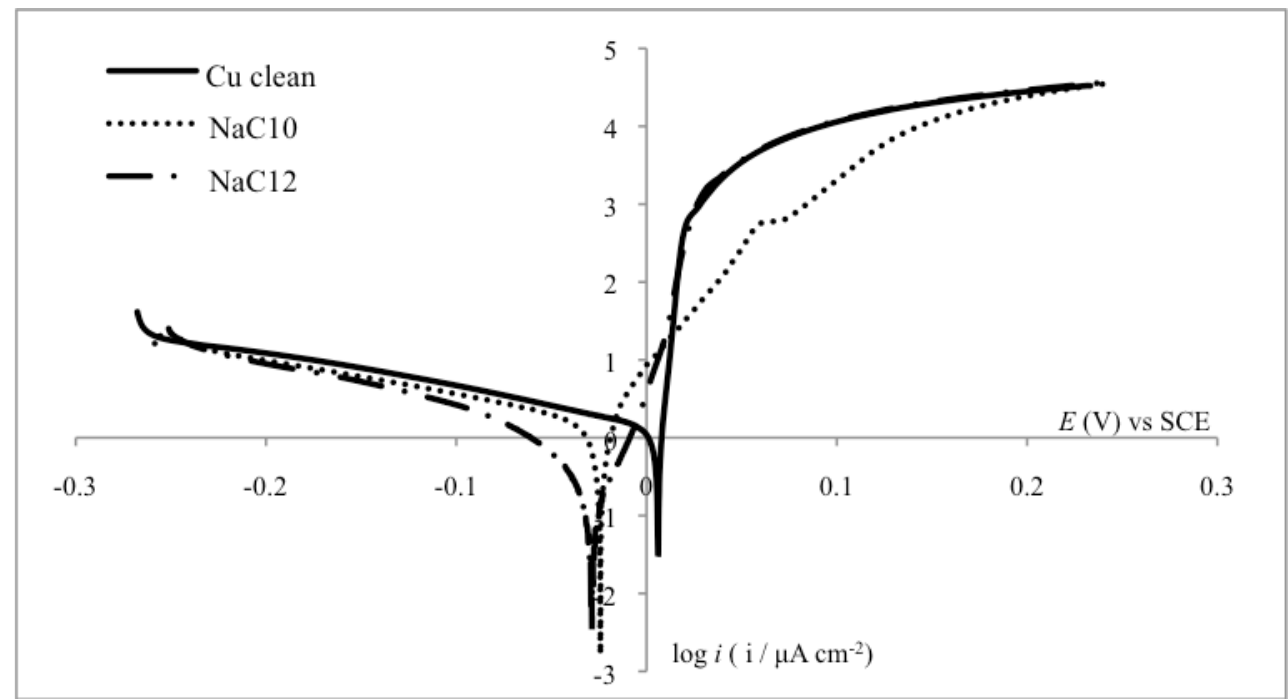

Fig. 6 Polarization curves (logarithmic scale) of a copper electrode modified with different carboxylates. The electrolyte is $0.1 \mathrm{M} \mathrm{Na}_{2} \mathrm{SO}_{4}$

Table 1 Polarization resistance $\left(R_{\mathrm{p}}\right)$ of the modified electrodes in $0.1 \mathrm{M} \mathrm{Na}_{2} \mathrm{SO}_{4}$

\begin{tabular}{l|c|c}
\hline Cu carboxylate & $\boldsymbol{R}_{\mathbf{p}}\left(\mathbf{\Omega} \mathbf{~ m m}^{\mathbf{2}}\right)$ & $\mathbf{R S D}(\mathbf{\%})$ \\
\hline Uncoated copper & $1.50 \times 10^{5}$ & 36 \\
$\mathrm{CuC}_{7}$ & $2.41 \times 10^{5}$ & 29 \\
$\mathrm{CuC}_{10}$ & $3.78 \times 10^{5}$ & 43 \\
$\mathrm{CuC}_{12}$ & $1.14 \times 10^{6}$ & 54 \\
\hline
\end{tabular}

Table 2 Corrosion current density $\left(i_{\text {corr }}\right)$ of the modified electrodes in $0.1 \mathrm{M} \mathrm{Na}_{2} \mathrm{SO}_{4}$

\begin{tabular}{l|c|c|c}
\hline \multicolumn{1}{c|}{ Cu carboxylate } & $\boldsymbol{i}_{\text {corr }}\left(\mathbf{A} \mathbf{~ m m}^{-\mathbf{2}}\right)$ & RSD (\%) & IE (\%) \\
\hline Uncoated copper & $1.36 \times 10^{8}$ & 61 & - \\
$\mathrm{CuC}_{10}$ & $1.07 \times 10^{8}$ & 30 & 21 \\
$\mathrm{CuC}_{12}$ & $7.99 \times 10^{9}$ & 73 & 41 \\
\hline
\end{tabular}

